\title{
Produtividade de alface e rabanete em cultivo consorciado estabelecido em diferentes épocas e espaçamentos entre linhas
}

\author{
Arthur Bernardes Cecílio Filho" ${ }^{1 *}$; Bráulio Luciano A Rezende"; Gustavo Henrique D Canato ${ }^{2}$

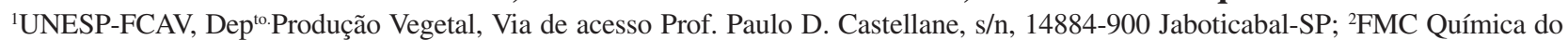 \\ Brasil Ltda, Av. Dr. José Bonifácio Coutinho Nogueira, 150, 1 A, 13091-611 Campinas-SP; *Bolsista pesquisador do CNPq: E-mail: \\ rutra@fcav.unesp.br, blrezende@ig.com.br.
}

\section{RESUMO}

O trabalho foi conduzido na UNESP, Jaboticabal-SP, de maio a agosto de 2001, com objetivo de avaliar a produtividade de alface e rabanete em função do espaçamento e da época de estabelecimento do consórcio. Os 14 tratamentos foram avaliados em blocos ao acaso, com quatro repetições e parcelas de 20 plantas, sendo resultado da combinação dos fatores espaçamento entre linhas da alface $(0,3 \mathrm{e}$ 0,4 m), sistemas de cultivo (consórcio e monocultivo) e época de semeadura do rabanete $(0 ; 7$ e 14 dias após o transplantio da alface). As cultivares utilizadas foram Tainá (alface) e Crimson Gigante (rabanete). Devido ao estande mais elevado, a produtividade do rabanete em monocultivo foi superior à melhor produtividade obtida em

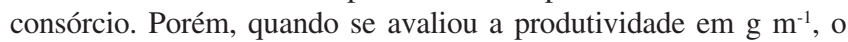
melhor resultado $\left(518,8 \mathrm{~g} \mathrm{~m}^{-1}\right)$ foi observado em cultivo consorciado com semeadura do rabanete 14 dias após o transplantio de alface (DAT), sendo significativamente superior à produtividade obtida no monocultivo. Observou-se ainda incremento significativo na produtividade de raízes comerciais de rabanete à medida em que se atrasou o estabelecimento do consórcio. $\mathrm{O}$ espaçamento da alface não influenciou significativamente a massa fresca da parte aérea (MFPA) das plantas das laterais do canteiro. Entretanto, houve redução significativa na MFPA das plantas internas ao canteiro quando o espaçamento entre linhas foi reduzido de $0,40(460,3 \mathrm{~g})$ para $0,30 \mathrm{~m}$ (321,1 g). A MFPA de plantas de alface cultivadas em consórcio e situadas nas duas linhas centrais do canteiro (MFPAIn $=434,9 \mathrm{~g}$ ) não diferiu significativamente da obtida em monocultivo $(542,9 \mathrm{~g})$ quando as culturas foram implantadas na mesma data. $\mathrm{O}$ mesmo foi observado para plantas situadas nas laterais do canteiro (MFPAEx $=$ 529,2 g), quando o consórcio foi estabelecido até 7 DAT da alface. Em consórcios estabelecidos a partir desta época, a produção de alface foi sempre menor que em monocultivo. Independente do espaçamento entre linhas e do tempo de semeadura do rabanete em relação ao transplantio da alface, todos os índices de Uso Eficiente da Terra (UET) foram maiores que 1,0.

Palavras-chave: Lactuca sativa, Raphanus sativus, sistema de cultivo, consorciação.

\section{ABSTRACT}

Lettuce and radish productivity in intercropping systems as influenced by starting time and row spacings

An intercropping system between lettuce and radish was devised so as to study the effects on yield of different starting moments for the intercropping, as well as different row distances. The experiment was carried out at UNESP, in Jaboticabal, from May to August, 2001. Fourteen treatments were distributed in a randomized complete block design, with four replicates. Each plot consisted of 20 plants which resulted from the combination of the following factors: two distances between rows ( 0.3 and $0.4 \mathrm{~m}$ ), two cultivation systems (intercropping and sole crop), and three radish sowing moments ( $0 ; 7$; and 14 days after lettuce transplantation), meaning that the intercropping system started at three different moments. Cultivars Taiá (lettuce) and Crimson Gigante (radish) were used. Due to a level stand, radish as a sole crop yielded more than the highest yield under intercropping. Nevertheless, when yield was evaluated per area unit $\left(\mathrm{g} \mathrm{m}^{-1}\right)$, the highest yield $\left(518.8 \mathrm{~g} \mathrm{~m}^{-1}\right)$, was significantly higher than when radish was cultivated as a sole crop, wich resulted from the intercropping established by sowing radish 14 days after lettuce transplantation (DAT). The delay in radish sowing resulted in significant increment in yield of commercial radish roots. The distance between lettuce rows had no significant effect on fresh mass of the aerial part (MFPA) of the border row plants. However, MFPA of the inner row plants decreased significantly when the distance between rows was reduced

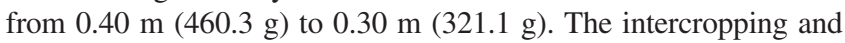
the single crop systems did not lead to significant differences in the yield of lettuce plants in the inner row (434.9 and $542.9 \mathrm{~g}$, respectively) when lettuce and radish cultivation started at the same moment. A similar behavior was observed for border row plants when the intercropping took place up to 7 DAT. When the intercropping was established later, the yield of lettuce as a single crop was always higher than when intercropped. Independently of the intercropping system and distance between plant rows, the Land Efficiency Use indices were always higher than 1.0.

Keywords: Lactuca sativa, Raphanus sativus, cultivation system, intercropping.

\section{(Recebido em 22 de novembro de 2005; aceito em 20 de abril de 2007)}

$\mathrm{O}$ sistema de cultivo consorciado constitui-se no cultivo simultâneo de duas ou mais espécies em uma mesma área de terra, por um período comum de ciclo das mesmas (Willey, 1979), que não necessariamente precisam ser semeadas conjuntamente (Chagas \& Vieira, 1984). Esta forma de cultivo per- mite maior densidade de plantas por unidade de área que um sistema de monocultivo, obtendo-se assim, melhor cobertura do solo, redução da incidência de plantas daninhas e maior proteção do solo contra a erosão (Beets, 1975; Zaffaroni, 1987). Também pode proporcionar um aumento na renda líquida do cultivo aos agricultores (Gode \& Bobde, 1993; Dubey \& Kulvi, 1995).

O grande desafio para o sucesso de sistemas consorciados está na capacidade em determinar quais espécies devem ser utilizadas e, principalmente, o manejo do consórcio (Ceretta, 1986). Segundo este autor, a eficiência de um sis- 
tema de consorciação de culturas fundamenta-se na complementaridade entre as espécies envolvidas, sendo que será tanto maior à medida em que se consegue minimizar o efeito negativo estabelecido de uma espécie sobre a outra. Neste sentido, escolher criteriosamente as culturas componentes e a época de seus respectivos plantios é de fundamental importância, para que se possa propiciar máxima exploração das vantagens do sistema consorciado (Trenbath, 1975). Acredita-se em grande contribuição deste sistema de cultivo para a atividade olerícola, não só pelas vantagens que proporciona, mas, principalmente, pela possibilidade de situar a olericultura dentro do contexto de agricultura com menor impacto ambiental, uma vez que o cultivo consorciado caracteriza-se pela otimização de insumos e, a olericultura, por uso intensivo de recursos naturais e de insumos agrícolas.

$\mathrm{Na}$ olericultura, o consórcio tem potencial de utilização por pequenos produtores, sendo uma técnica de fácil implementação. Segundo Camargo Filho \& Mazzei (2001), mais de $75 \%$ da produção de hortaliças no Brasil é proveniente de agricultura familiar, portanto, de pequenos produtores; fato que faz da consorciação uma técnica de cultivo bastante interessante de ser estudada, aprimorada e difundida. Recentemente, alguns trabalhos têm demonstrado a viabilidade do cultivo consorciado de hortaliças. A consorciação entre cenoura e rabanete determinou maior acúmulo de massa seca e fresca de raízes tuberosas de rabanete em relação ao monocultivo e maior receita bruta foi obtida quando o consórcio foi estabelecido por ocasião do segundo desbaste da cenoura (Ferreira \& Cecílio Filho, 2001).

No consórcio de beterraba com rúcula, Nardin et al. (2002) e Cecílio Filho et al. (2003) observaram que a produtividade da beterraba em monocultivo não diferiu significativamente da obtida em cultivo consorciado. Entretanto, a produtividade da rúcula em monocultivo foi superior à obtida em consórcio e à medida que a semeadura da rúcula foi sendo realizada mais tardiamente em relação ao transplantio da beterraba, menor foi a sua produtivida- de, demonstrando forte competição da beterraba sobre a rúcula, especialmente quanto à luz. Levando em consideração o índice de uso eficiente da terra (UET) e a receita estimada, os autores verificaram que a consorciação das culturas foi vantajosa, obtendo-se um acréscimo de $87 \%$ na receita bruta quando o consórcio foi estabelecido com a semeadura da rúcula conjuntamente ao transplantio da beterraba.

Em cultivo protegido, avaliando épocas de transplantio da alface em relação ao tomateiro, Rezende et al. (2005) observaram que no consórcio a produtividade do tomate não foi prejudicada pela alface. O maior índice de uso eficiente da terra (UET) foi observado quando o consórcio com transplantio da alface foi estabelecido até 14 dias após o transplantio do tomateiro. A partir de então, a produtividade da cultura de alface foi severamente reduzida, inviabilizando o cultivo consorciado.

Cecílio Filho \& May (2002) observaram que o crescimento e a produtividade do rabanete foi maior em consorciação com a alface do que em monocultivo. O consórcio estabelecido com a semeadura do rabanete no mesmo dia do transplantio da alface, proporcionou receita de $\mathrm{R} \$ 26.660,55 \mathrm{ha}^{-1}$, enquanto o monocultivo da alface possibilitou uma receita de $\mathrm{R} \$ 18.036,29$ $\mathrm{ha}^{-1}$. No consórcio entre rabanete e alface, Rezende et al. (2003) constataram que a maior produtividade da cultura do rabanete foi conseguida em cultivo consorciado com a alface, quando foi semeado sete dias após o transplantio da alface. Por outro lado, o rabanete não afetou a alface pois a produtividade desta em consórcio não diferiu significativamente da obtida em monocultivo.

Nesse contexto, o presente trabalho teve por objetivo avaliar a produtividade das culturas da alface e do rabanete sob diferentes épocas de estabelecimento do consórcio e espaçamentos entre linhas da alface.

\section{MATERIAL E MÉTODOS}

$\mathrm{O}$ experimento foi conduzido em campo, no período de maio a agosto de 2001, na UNESP, Câmpus de
Jaboticabal (SP) $\left(21^{\circ} 15^{\prime} 22^{\prime \prime} \mathrm{S}\right.$, $48^{\circ} 15^{\prime} 58^{\prime \prime} \mathrm{W}$, altitude de 575 metros). O solo da área experimental foi classificado Latossolo Vermelho Eutroférrico típico de textura muita argilosa, A moderado caulinítico-oxídico, relevo suave ondulado a ondulado (Oliveira et al., 1999). A análise química do solo apresentou $\mathrm{pH}\left(\mathrm{CaCl}_{2}\right)$ de 6,$1 ; 22 \mathrm{~g} \mathrm{dm}^{-3}$ de matéria orgânica, $78 \mathrm{mg} \mathrm{dm}^{-3}$ de $\mathrm{P}$ (resina). Em mmol $\mathrm{dm}^{-3}$, observou-se 2,6; 65 e 20 de K, Ca e de Mg, e V\% de 71. Após o preparo do solo, foram preparados os canteiros.

Foi realizada calagem para elevar a saturação de bases a $80 \%$. As adubações de plantio e de cobertura para as culturas da alface e do rabanete basearam-se na análise do solo e recomendações de Trani et al. (1997a, b). Para a alface, a adubação de plantio foi de $100 \mathrm{~g} \mathrm{~m}^{-2}$ de superfosfato simples, $10 \mathrm{~g} \mathrm{~m}^{-2}$ de cloreto de potássio e $20 \mathrm{~g} \mathrm{~m}^{-2}$ de nitrocálcio e, para o rabanete, $100 \mathrm{~g} \mathrm{~m}^{-2} \mathrm{de}$ superfosfato simples, $10 \mathrm{~g} \mathrm{~m}^{-2}$ de cloreto de potássio e $10 \mathrm{~g} \mathrm{~m}^{-2}$ de nitrocálcio. A adubação de cobertura para a alface foi realizada $10 ; 20$ e 30 dias após o transplantio (DAT) com $2 \mathrm{~g} \mathrm{planta}^{-1}$ de nitrocálcio e $2 \mathrm{~g}$ planta $^{-1}$ de cloreto de potássio, 30 DAT. Para o rabanete, foram aplicados $5 \mathrm{~g}$ de nitrocálcio por metro linear 10; 17 e 24 dias após a semeadura e $2 \mathrm{~g}$ de cloreto de potássio por metro linear nas duas últimas coberturas. Para os consórcios, foi realizada a adubação de plantio conforme a recomendação para a alface. Em cobertura, realizaram-se as adubações para as duas hortaliças (Trani et al, 1997 a, b).

O delineamento experimental foi blocos casualizados, com quatro repetições. Foram avaliados 14 tratamentos, que resultaram de combinações dos fatores: sistemas de cultivo (consórcio e monocultivo), épocas de semeadura do rabanete $(0 ; 7$ e 14 dias após o transplantio da alface) e espaçamentos entre linhas da alface $(0,30$ e $0,40 \mathrm{~m})$. Os tratamentos 1; 2 e 3 corresponderam aos cultivos consorciados de alface e rabanete instalados 0; 7 e 14 DAT da alface; o tratamento 4 , ao monocultivo de alface e, os tratamentos 5; 6 e 7, aos monocultivos de rabanete instalados nas mesmas épocas de estabelecimento dos consórcios, no espaçamento entre linhas 
da alface de $0,30 \mathrm{~m}$. Os tratamentos 8 a 14 correspondem à descrição dos tratamentos 1 a 7 , porém no espaçamento de 0,40 m entre linhas da alface.

A unidade experimental foi constituída por 20 plantas de alface no espaçamento de $0,30 \times 0,30 \mathrm{~m}$, em quatro linhas de plantio, e 21 plantas no espaçamento de 0,40 x $0,30 \mathrm{~m}$ (três linhas de plantio). O rabanete foi semeado nas entrelinhas da alface e, portanto, tinham-se três e duas linhas de plantas, respectivamente, nos espaçamentos de 0,30 e $0,40 \mathrm{~m}$ entre linhas da alface. No monocultivo, o rabanete foi semeado em espaçamento tradicional de $0,25 \mathrm{~m}$ entre linhas, portanto quatro linhas longitudinais. Foi realizado desbaste no rabanete dez dias após a emergência, deixando-se $0,05 \mathrm{~m}$ entre plantas na linha. A alface foi semeada em bandejas de poliestireno expandido para 288 mudas e trasplantada para o canteiro com quatro folhas, 34 dias após a semeadura. As cultivares utilizadas foram Tainá para alface e Crimson Gigante para o rabanete.

As produções de raízes comerciais e não comerciais de rabanete foram determinadas pelos diâmetros das raizes superior e inferior a $20 \mathrm{~mm}$, respectivamente. A produção de massa fresca da parte aérea da alface (MFPA) foi avaliada separadamente para as plantas situadas nas laterais do canteiro (MFPAEx) e para as plantas situadas internamente ao canteiro (MFPAIn), com objetivo de melhor constatar o efeito do consórcio sobre as plantas componentes. A alface completou seu ciclo em 103 dias, enquanto para o rabanete, a colheita procedeu-se, em média, com 41 dias.

Para o cálculo do índice de uso eficiente da terra (UET), em função dos sistemas de cultivo e época de estabelecimento do consórcio, foi utilizada a fórmula proposta por Willey (1979): $\mathrm{UET}=(\mathrm{Yab} / \mathrm{Yaa})+(\mathrm{Yba} / \mathrm{Ybb})$, onde, Yab é a produção da cultura "a" em consórcio com a cultura "b"; Yba é a produção da cultura "b" em consórcio com a cultura "a"; Yaa é a produção da cultura "a" em monocultivo e Ybb é a produção da cultura "b" em monocultivo. Dado a diferença de estande existente em função do sistema de cultivo, as pro-

Tabela 1. Produtividade de raízes comerciais de rabanete em função da época de semeadura e sistema de cultivo (Commercial yield of radish roots as result of sowing time and cropping system). Jaboticabal, UNESP, 2004.

\begin{tabular}{lcc}
\hline \multirow{2}{*}{ Época de semeadura } & \multicolumn{2}{c}{ Sistema de cultivo } \\
\cline { 2 - 3 } & \multicolumn{3}{c}{ Consórcio } & Monocultivo \\
\cline { 2 - 3 } & & \\
\hline Rabanete 0 DAT & & \\
Rabanete 7 DAT & $300,6 \mathrm{Ca}$ & $281,7 \mathrm{Ba}$ \\
Rabanete 14 DAT & $398,2 \mathrm{Ba}$ & $370,3 \mathrm{Aa}$ \\
\hline CV $(\%)$ & $518,8 \mathrm{Aa}$ & $381,2 \mathrm{Ab}$ \\
\hline
\end{tabular}

Médias seguidas de mesma letra minúscula na linha e maiúscula na coluna não diferem entre si pelo teste de Tukey, $\mathrm{P}<0,05$ (Means followed by the same small letters in the line and capital in the column did not differ from each other, Tukey's test, $\mathrm{p}<0.05$ ).

${ }^{1} \mathrm{DAT}=$ dias ápos o transplantio da alface (days after lettuce transplanting)

duções de alface foram calculadas em $\mathrm{kg} \mathrm{m}^{-2}$ (MFPAEx + MFPAIn), utilizando-se como média das densidades de plantio nos espaçamentos $0,30 \times 0,30$ m $\left(11,11\right.$ plantas $\left.\mathrm{m}^{-2}\right)$ e $0,40 \times 0,30 \mathrm{~m}$ $\left(8,33\right.$ plantas $\left.\mathrm{m}^{-2}\right)$. Para cálculo da produção de rabanete $\left(\mathrm{kg} \mathrm{m}^{-2}\right)$ foram consideradas duas linhas de rabanete no consórcio com alface em espaçamento de $0,40 \mathrm{~m}$, três linhas na alface cultivada em espaçamento de 0,30 m entre linhas e quatro linhas em monocultivo. Considerou-se, para avaliação das características, a área útil de $1 \mathrm{~m}^{2}$ central da parcela, excluindo-se a parte inicial e final das linhas de plantas de cada parcela.

\section{RESULTADOS E DISCUSSÃO}

A produtividade $\left(\mathrm{kg} \mathrm{m} \mathrm{m}^{-2}\right)$ do monocultivo de rabanete foi superior à melhor produtividade obtida em consorciação. No entanto, este resultado não foi devido ao efeito negativo da alface sobre o rabanete mas, sim, pelo diferencial de estande. Enquanto no monocultivo existiam quatro linhas de rabanete dispostas no sentido longitudinal do canteiro de $1,1 \mathrm{~m}$ de largura e cerca de 520.000 plantas por hectare; nos consórcios estabelecidos com alface cultivado em espaçamento de 0,30 $\mathrm{m}$ e 0,40 m entre linhas existiam três e duas linhas de rabanete e cerca de 382.000 e 260.000 plantas por hectare, respectivamente.

Eliminando-se o efeito da população de plantas sobre a produção do rabanete e avaliando-se a produtividade da cultura em gramas por metro e não por área $\left(\mathrm{m}^{2}\right)$, verificou-se que a maior pro- dutividade $\left(518,8 \mathrm{~g} \mathrm{metro}^{-1}\right)$ de rabanete foi observada em cultivo consorciado, estabelecido pela semeadura do rabanete 14 dias após o transplantio de alface (Tabela 1), sendo significativamente superior à produtividade obtida no monocultivo em aproximadamente $26 \%$. Em consórcio, observou-se incremento na produtividade de raízes comerciais de rabanete à medida em que se atrasou a semeadura do rabanete em relação ao transplantio da alface, ou seja, a produtividade elevou-se com o atraso no estabelecimento do consórcio. Esta constatação provavelmente resulta do benefício da cobertura do solo pela alface, diminuindo a oscilação térmica e hídrica na entre linha, fatores estes bastante estressantes à cultura do rabanete.

Rezende et al. (2003) também verificaram maior produtividade do rabanete em consórcio com a alface, porém quando este foi estabelecido pela semeadura do rabanete sete dias após o transplantio da alface, em cultivo de verão. Observa-se, portanto, grande semelhança entre os resultados (vantagem do cultivo consorciado) daquele trabalho e os obtidos nesse experimento, conduzido no inverno; diferindo entre si pela época em que obteve-se a máxima produtividade decorrente das condições ambientais dos períodos de cultivo. Neste estudo, o desenvolvimento da alface, em campo, em virtude das baixas temperaturas, foi mais lento (69 dias) do que o observado por Rezende et al. (2003) (58 dias) e, consequentemente, as vantagens percebidas pelo rabanete quanto à presença da alface também se manifestaram mais tardiamente. 
Tabela 2. Massa fresca da parte aérea de plantas de alface situadas interna (MFPAin) e externamente (MFPAex) ao canteiro, em função do espaçamento (Fresh weight of the aerial part of border row (MFPAex) and inner row (MFPAin) lettuce plants as result of plant spacings). Jaboticabal, UNESP, 2004.

\begin{tabular}{lcc}
\hline \multirow{2}{*}{ Espaçamento } & MFPAin & MFPAex \\
\cline { 2 - 3 } & \multicolumn{3}{c}{ g planta $^{-1}$} \\
\hline $0,30 \mathrm{~m}$ & $321,1 \mathrm{~B}$ & $519,8 \mathrm{~A}$ \\
$0,40 \mathrm{~m}$ & $460,3 \mathrm{~A}$ & $556,9 \mathrm{~A}$ \\
\hline $\mathrm{CV}(\%)$ & 25,32 & 12,96 \\
\hline
\end{tabular}

Médias seguidas de mesma letra na coluna não diferem entre si pelo teste de Tukey, $\mathrm{p}<0,05$ (Means followed by the same letter in the column did not differ from each other, Tukey's test, $\mathrm{p}<0.05)$.

Tabela 3. Massa fresca da parte aérea de plantas de alface situadas interna (MFPAIn) e externamente (MFPAEx) ao canteiro, em função do sistema de cultivo e época de estabelecimento do consórcio (Fresh weight of the aerial part of border (MFPAex) and inner rows (MFPAin) lettuce plants as result of cropping system and the intercropping starting time). Jaboticabal, UNESP, 2004.

\begin{tabular}{lcl}
\hline \multirow{2}{*}{ Sistemas de cultivo } & MFPAln & MFPAEx \\
\cline { 2 - 3 } & \multicolumn{2}{c}{ g planta $^{-1}$} \\
\hline Alface + Rabanete 0 DAT & $434,9 \mathrm{AB}$ & $564,7 \mathrm{AB}$ \\
Alface + Rabanete 7 DAT & $311,0 \mathrm{BC}$ & $529,2 \mathrm{AB}$ \\
Alface + Rabanete 14 DAT & $274,0 \mathrm{C}$ & $470,0 \mathrm{~B}$ \\
Monocultivo & $542,9 \mathrm{~A}$ & $589,6 \mathrm{~A}$ \\
\hline CV (\%) & 25,32 & 12,96 \\
\hline
\end{tabular}

Médias seguidas de mesma letra na coluna não diferem entre si pelo teste de Tukey, $\mathrm{p}<0,05$ (Means followed by the same letter in the column did not differ from each other by, Tukey's test, $\mathrm{p}<0.05$ ).

${ }^{1} \mathrm{DAT}=$ dias ápos o transplantio da alface (days after lettuce transplanting)

Tabela 4. Produtividade e índices de uso eficiente da terra (UET) dos cultivos consorciados em função do espaçamento e da época de estabelecimento do consórcio (Productivity and land use efficiency index of the intercroppings as result of spacing among plants and intercropping starting time). Jaboticabal, UNESP, 2004.

\begin{tabular}{|c|c|c|c|}
\hline \multirow{3}{*}{ Sistemas de cultivo } & \multicolumn{2}{|c|}{ Produtividade $\left(\mathrm{kg} \mathrm{m}^{-2}\right)$} & \multirow{2}{*}{ UET } \\
\hline & Alface & Rabanete & \\
\hline & \multicolumn{3}{|c|}{ Espaçamento da alface de $0,30 \mathrm{~m}$ entre linhas } \\
\hline Consórcio 0 DAT & 4,7 & 0,9 & 1,57 \\
\hline Consórcio 7 DAT & 4,4 & 1,2 & 1,50 \\
\hline Consórcio 14 DAT & 3,5 & 1,6 & 1,57 \\
\hline Monocultivo de alface & 6,1 & -- & -- \\
\hline Monocultivo de rabanete 0 DAT & - & 1,14 & -- \\
\hline Monocultivo de rabanete 7 DAT & -- & 1,58 & -- \\
\hline \multirow[t]{2}{*}{ Monocultivo de rabanete 14 DAT } & - & 1,54 & - \\
\hline & \multicolumn{3}{|c|}{ Espaçamento da alface de $0,40 \mathrm{~m}$ entre linhas } \\
\hline Consórcio 0 DAT & 4,8 & 0,6 & 1,52 \\
\hline Consórcio 7 DAT & 3,7 & 0,8 & 1,33 \\
\hline Consórcio 14 DAT & 3,6 & 1,0 & 1,43 \\
\hline Monocultivo de alface & 4,9 & - & -- \\
\hline Monocultivo de rabanete 0 DAT & -- & 1,1 & -- \\
\hline Monocultivo de rabanete 7 DAT & - & 1,4 & - \\
\hline Monocultivo de rabanete 14 DAT & -- & 1,5 & -- \\
\hline
\end{tabular}

Nota-se que não houve diferença significativa entre de massa fresca da par- te aérea da alface (MFPA) para as plantas nas laterais do canteiro em relação ao espaçamento. Entretanto, para as plantas internas ao canteiro, observouse diferença significativa, sendo que no espaçamento de $0,30 \times 0,30 \mathrm{~m}$ houve redução de $30,2 \%$ na massa fresca da parte aérea das plantas de alface, em relação ao espaçamento de $0,40 \mathrm{~m}$ entre plantas (Tabela 2). As produções de massa fresca da parte aérea de plantas de alface cultivadas em consórcio e situadas nas duas linhas centrais do canteiro (MFPAIn) não diferiram da obtida em monocultivo, quando as culturas foram implantadas na mesma data. O mesmo foi observado para plantas situadas nas laterais do canteiro (MFPAEx), quando o consórcio foi estabelecido até 7 dias após o transplantio da alface (DAT). Em consórcios estabelecidos 14 DAT, a produção de alface foi sempre menor que em monocultivo, quer seja para plantas situadas nas laterais ou internas ao canteiro (Tabela 3 ), atingindo $50 \%$ de redução na massa fresca de plantas localizadas internamente.

A maior competição sofrida pelas plantas internas de alface se deve à presença do rabanete lateralmente às mesmas, enquanto as plantas localizadas nas linhas laterias do canteiro somente receberam pressão do rabanete por competição de um de seus lados. Já a maior redução da massa da alface com a semeadura tardia do rabanete, deve-se às baixas temperaturas ocorridas na época do cultivo, que determinaram o maior período de crescimento (69 dias) no campo e, em consequência, fizeram coincidir os períodos de maior acúmulo de massa da parte aérea da alface e rabanetes semeados mais tardiamente.

O menor espaçamento entre linhas da alface afetou significativa e negativamente a produção de MFPA das plantas de alface situadas internamente ao canteiro. Verificou-se redução de aproximadamente $30 \%$ na MFPA de alface cultivada no espaçamento de 0,30 x 0,30 $\mathrm{m}\left(321,1 \mathrm{~g} \mathrm{planta}^{-1}\right)$ em relação à alface cultivada a $0,40 \times 0,30 \mathrm{~m}$ (460,3 g plan$\left.\mathrm{ta}^{-1}\right)$. Para alfaces localizadas nas laterais do canteiro não houve influência do espaçamento sobre a MFPA (média de 538,4 g planta $^{-1}$ ).

Independente do espaçamento entre linhas e do tempo de semeadura do rabanete em relação ao transplantio da 
alface todos os índices de Uso Eficiente da Terra (UET) foram maiores do que 1,0 (Tabela 4), demonstrando a vantagem do consórcio em relação ao monocultivo para a produção de alimentos por unidade de área. O maior índice de uso eficiente da terra foi obtido para o consórcio estabelecido 0 e 14 dias após o transplantio da alface no espaçamento 0,30 m entre linhas (Tabela 4), demonstrando que para a obtenção da mesma quantidade de alimento produzida em um hectare de consórcio é preciso $57 \%$ de incremento na área dos monocultivos. A obtenção dos mesmos índices UET $(1,57)$ em diferentes situações de cultivo consorciado (0 e 14 DAT da alface, com 0,30 m entre linha) demonstra efeitos distintos das interações interespecíficas. No consórcio estabelecido pela semeadura do rabanete conjuntamente ao transplantio da alface ( 0 DAT), o índice foi fortemente favorecido pela produtividade da alface, enquanto no consórcio em que o rabanete foi semeado 14 DAT da alface foi a produção de rabanete que mais contribuiu para a obtenção do mesmo índice. Tal resultado denota a necessidade de o produtor definir a data de estabelecimento do consórcio em função da cultura considerada como principal, normalmente estabelecida pela análise de suas expressões econômicas na região e época do cultivo.

Os resultados deste trabalho mostraram que os índices UET se assemelham quando comparados dentro de um mesmo espaçamento de alface, mas maiores índices foram obtidos em cultura mais adensada. Por outro lado, os mesmos resultados demonstram que estes índices, embora semelhantes, foram obtidos com participações distintas das hortaliças alface e rabanete. De modo geral, verificou-se que a produtividade de raízes comerciais de rabanete aumentou com a sua semeadura mais tardia em relação ao transplantio da alface, enquanto que a produtividade dessa diminui. Deste modo, o cultivo consorciado das culturas de alface e rabanete demonstrou ser vantajoso em todas as épocas de estabelecimento de consórcio avaliadas, levando em consideração o índice de uso eficiente da terra.

\section{REFERÊNCIAS}

BEETS WC. 1975. Multiple-cropping. World Crop Livest 29: 25-27.

CAMARGO FILHO WP; MAZZEI AR. 2001. Mercado de verduras: planejamento e estratégia na comercialização. Informações Econômicas 31: 45-54

CECÍLIO FILHO AB; MAY A. 2002. Produtividade das culturas de alface e rabanete em função da época de estabelecimento do consórcio, em relação a seus monocultivos. Horticultura Brasileira 20: 501-504.

CECÍLIO FILHO AB; TAVEIRA MCGS; GRANGEIRO LC. 2003. Productivity of the beet culture in function of time of establishment of the intercropping with rocket. Acta Horticulturae 607: 91-95.

CERETTA CA. 1986. Sistema de cultivo de mandioca em fileiras simples e duplas em monocultivo e consorciada com girassol. Porto Alegre: UFRGS. 122p. (Tese mestrado).

CHAGAS JM; VIEIRA C. 1984. Consórcio de culturas e razões de sua utilização. Informe Agropecuário 10: 10-12.

DUBEY D; KULVI GS 1995. Performace of sorghum (Sorghum bicolor) as influencied by intercropping and planting geometry. Indian Journal Agronomy 9: 353-356.

FERREIRA RP; CECÍLIO FILHO AB. 2001. Rendimento de raízes tuberosas de cenoura e rabanete em cultivo consorciado. Horticultura Brasileira 19: Suplemento. CD-ROM.
GODE DB; BOBDE GN. 1993. Intercropping of soybean sorghum. PKV - Research Journal 17: 128-129.

NARDIN RR; CATELAN F; CECÍLIO FILHO AB. 2002. Efeito da consorciação sobre as produtividades da rúcula e da beterraba estabelecida por transplantio de mudas. Horticultura Brasileira 20: Suplemento. CDROM.

OLIVEIRA JB; CAMARGO MN; ROSSI M; CALDERANO FILHO B. 1999. Mapa pedológicos do Estado de São Paulo: legenda expandida. Campinas: EMBRAPA Solos. 63 p.

REZENDE BLA; CANATO GHD; CECÍLIO FILHO AB. 2003. Productivity of lettuce and radish cultivations as a function of spacing and time of establishment of intercropping. Acta Horticulturae 607: 97-101.

REZENDE BLA; CANATO GHD; CECÍLIO FILHO AB. 2005. Produção das culturas consorciadas de tomate e alface em função da época de consorciação, em duas épocas de cultivo. Ciência e Agrotecnologia 29: 77-83.

TRANI PE; PASSOS FA; AZEVEDO FILHO JA. 1997. Alface, almeirão, chicória, escarola, rúcula e agrião d’agua. In: RAIJ B van; CANTARELLA H; QUAGGIO JA; FURLANI AMC. Recomendações de adubação e calagem para o estado de São Paulo. Campinas: IAC. p.168-169.

TRANI PE; PASSOS FA; TAVARES M; AZEVEDO FILHO JA. 1997. Beterraba, cenoura, nabo, rabanete e salsa. In: RAIJ B; CANTARELLA H; QUAGGIO JA; FURLANI AMC. Recomendações de adubação e calagem para o estado de São Paulo. Campinas: IAC, p.174.

TRENBATH BR. 1975. Plant interactions in mixed crop communities. In: PAPENDICK RI; SANCHES PA; TRIPLE GB. (Ed). Multiple cropping. Wisconsin: American Society of Agronomy p.129-160.

WILLEY RW. 1979. Intercropping: its importance and research needs. Part $1=$ Competition and yield advantages. Field Crops Abstract 32: 110.

ZAFFARONI E. 1987. Yield stability of sole and intercropping systems in the Northeast of Brazil. Pesquisa Agropecuária Brasileira 22: 393-99. 